\section{"Refractory Impetigo"}

"M.D." writes, in answer to Dr. L. I. Hardy's inquiry (September 10th, p. 538): I have never found a case of true impetigo fail to clear up quickly on the following oldfashioned prescription: argent. nitras, grains $x v, s p$. aeth. nitros., ad $3 \mathrm{i}$. Two or three applications are needed at daily intervals, all scabs having been removed before the first application. The silver solution deposits a brown stain, but this soon wears off. One need hardly point out how much cleaner this treatment is than the usual " messy" ointments.

\section{Softening the Beard}

Dr. A. L. MARTYN (Crantock), in reply to "W. D. B.'s" inquiry, recommends sponging the face with very warm water and using, a simple bristle brush previously softened by five minutes' immersion in hot water. Soap can be rubbed on first, but an improvement on this is to use a good shaving cream on the brush. He writes: Then gently work up a thick lather of medium consistency, but on the wet side. Avoid running the razor edge at too acute an angle. Bring the haft of the blade to the face and, if the edge be good, a minimum of irritation is produced. The circular, or scythe, method is desirable. All safety razors tend to drag the skin-the oblique cut is the easy cut. A highly tempered, first-class blade razor is always preferable to the visiting-card type of safety. I shall always remember the torment I went through when a safety razor was used on me by a well-meaning and zealous dresser prior to a surgical operation which I underwent.

“ M. D. C." writes: If “W. B. D." will add a few drops of glycerin to the final lathering shaving will be much more comfortable.

\section{Income Tax}

\section{Depreciation Allowance : Car}

"H. E. N." is in some doubt as to whether it is advisable in the long run to claim." depreciation" ; his accountant advises him to claim " renewals" instead.

** With respect we differ from “H. E. N.'s" accountant. It is true that if the rate of tax falls then the taxpayer may lose by having partly anticipated the renewal claim, but even then he will have had the use of the difference in tax for a year or two. On the other hand, where depreciation is not claimed, the practitioner on death or retirement will have a partially used car for which he has claimed, and can claim, no allowance. To some extent this happens through the falling price of cars. For instance, “H. E. N." bought a 12-h.p. car in 1927 for $£ 400$ and is now replacing it by a 9-h.p. car at $£ 300$. He has had $(£ 400-£ 134=) £ 266$ allowed him for depreciation, and will now get the excess of the $£ 134$ over the cash selling price as obsolescence-say, $(£ 134-£ 50=) £ 84$ - that is, he will have had total allowances of $£ 266+£ 84=£ 350$. A "renewals" claim would give him only $£ 300-£ 50=£ 250$.

\section{Resident Abroad}

" Perplexed" resides abroad. Last year his total income (from investments) amounted to $\mathbf{8 8 7}$, from which was deducted $£ 65$ income tax. Can he reclaim all or some of this amount?

** A person residing abroad remains liable to tax in respect of income-other than 5 per cent. War Loan-arising in the United Kingdom or Northern Ireland. $\mathrm{He}$ is, however, entitled to personal allowances, or rather to such proportion of them as his British income bears to his total income. Whether "Perplexed" can claim any repayment therefore depends on that proportion. If the whole of the British income is taxed in full he will certainly have some claim. The claim is usually somewhat troublesome, and he might do well to take expert advice on the actual factssay, from the income tax department of his bank.

\section{Deductible Expenses}

"W. A. B." inquires where he can find information with regard to all the allowances and expenses that can be claimed by a medical practitioner

** There is a chapter which will give "IV. A. B." what he seeks in a book published by Crosby Lockwood and Son at 4s. 6d., under the title of Income Tax and the Professional Man.

\section{LETTERS, NOTES, ETC.}

\section{Electric Heating Pads}

Mr. A. V. Summers, engineer and manager, "Thermega " Limited, replying to Colonel R. H. Elliot's letter on the above subject (Journal, October 1st, p. 652) points out that the accidents complained of have been caused by the failure of the flexible cable, apparently due to the type of threeheat control switch used in it. $\mathrm{He}$ writes: It must be remembered that the flexible cable of any electrical appliance is the part which receives most wear, and should accordingly be periodically examined, when most of such cases would obviously be avoided. The "Thermega Company has always adopted a large switch of entirely different type, with ample room for holding and operating, and special flexible cable.

Mr. F. W. Read (director, Medical Supply Association, Ltd.) writes: In this business we have been called upon to supply several thousands of electrical heating pads, and throughout the whole of our time we have never had any experience such as that referred to by Colonel Elliot. We think it would be difficult to see how a really serious fusing of the wires could have taken place had Colonel Elliot's circuit been guarded by the usual safety fuse which is invariably installed.

Lieut.-Colonel R. H. ElLIOT writes: My letter in your issue of October 1st has brought me a number of replies from manufacturers which show clearly that others have appreciated the risks I pointed out, and that some at least of the electric heating pads are now provided with a foolproof switch and with proper insulation of the flex. These were the two points I called attention to. After the experiences quoted in my previous letter I would urge that no medical man should prescribe an electric pad without making sure that these essential requisites are complied with.

\section{Inventions Great and Small}

This year's Exhibition of Inventions, which has been open for the last ten days at the Central Hall, Westminster is of particular interest in regard to the occupations of the inventors. Thus, to a " medical specialist" we owe an appliance for preventing hoax calls to the fire brigade, and to a dentist an electrically heated cabinet for drying clothes. Inappropriately enough, a verger has invented a loud speaker, while a barrister is responsible for pneumatic boots. A knee-pad, waterproof on the outside and lined with warm material to avoid chill, a check to prevent the slamming of the door or the rattle of the casement window, a box from which a match can be obtained by the use of one hand only, a scooter to carry one's suitcase, and a rubber silencer for the bottom of milk churns are amongst the other inventions. For motorists there are: collapsible shutters for controlling the temperature of the radiator; a glass for headlamps which absorbs the dazzling rays of light while allowing the horizontal rays to pass unimpaired; a safety device which instantaneously locks the whole group of nuts holding the wheel to its hub against vibration and rotation; and electrical means, operated without removing the hand from the steering-wheel, for the distribution of grit on the wheel's track just before braking or cornering. As for motor-car thieves, one device automatically locks all the doors, the bonnet, and the gear lever, disconnects the ignition and lighting system, and applies the brakes; while another, when any unauthorized person attempts to drive the car, causes the word " stolen" to appear on an illuminated metal plate. It should be added that this is the eighth year of this exhibition, which includes inventions from Germany and other European countries, the United States, and the British Dominions.

\section{Corrigendum}

In our annotation entitled " Research on food problems" (Journal, October 8th, p. 682, line 10), 106 was printed in error for $10^{6}$ in recording the number of organisms present per square centimetre of meat surface.

\section{Vacancies}

Notifications of offices vacant in universities, medical colleges, and of vacant resident and other appointments at hospitals, will be found at pages $53,54,55,58$, and 59 of our advertisement columns, and advertisements as to partnerships, assistantships, and locumtenencies at pages 56 and 57.

A short summary of vacant posts notified in the advertisement columns appears in the Supplement at page 211 . 